Portland State University

PDXScholar

\title{
A Behavioral Study of a Small Group of Pikas (Ochotona Princeps) On MT. Hood, Oregon
}

Nancy A. Ewen Frazier
Portland State University

Follow this and additional works at: https://pdxscholar.library.pdx.edu/open_access_etds

Part of the Biology Commons, and the Other Animal Sciences Commons Let us know how access to this document benefits you.

\section{Recommended Citation}

Frazier, Nancy A. Ewen, "A Behavioral Study of a Small Group of Pikas (Ochotona Princeps) On MT. Hood, Oregon" (1977). Dissertations and Theses. Paper 2518.

https://doi.org/10.15760/etd.2515

This Thesis is brought to you for free and open access. It has been accepted for inclusion in Dissertations and Theses by an authorized administrator of PDXScholar. Please contact us if we can make this document more accessible: pdxscholar@pdx.edu. 
AN ABSTRACT OF THE THESIS OF Nancy A. Ewen Frazier for the Master of Science in Biology presented May 20, 1977.

Title: A Behavioral Study of a Small Group of Pikas (Ochotona princeps) on Mt. Hood, Oregon.

APPROVED BY MENBERS OF THE THESIS COMMITTEE:

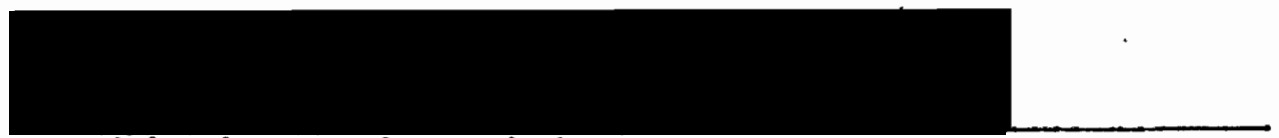

Richard B. Forbes, Chairman

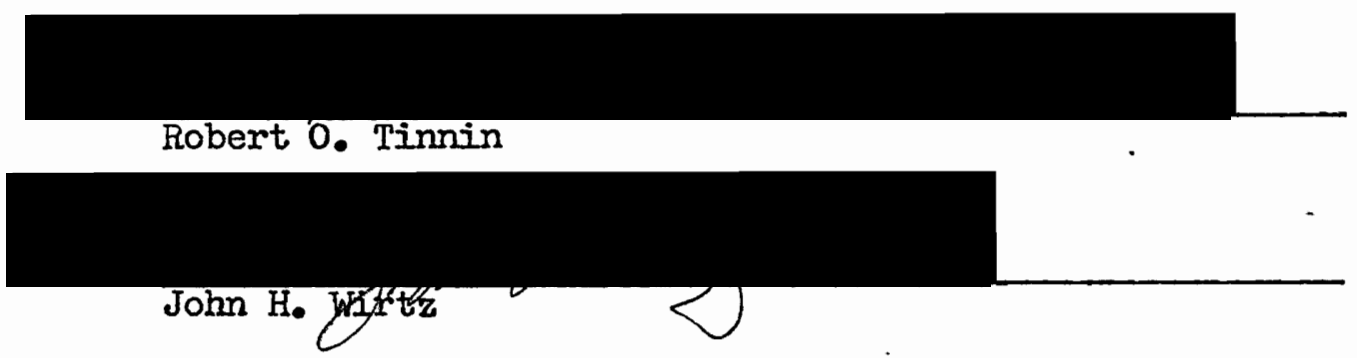

Observations of à small group of pikas, (Ochotona princeps) occupying a southwest facing roadfili on Mt. Hood, Oregon (1518 m) were made during the fall of 1976. Territorial sizes of $305.5 \mathrm{~m}^{2}$ and $121 \mathrm{~m}^{2}$ were determined based on territorial displays. These territories were compared with those observed in other studies. The mean distance to the nearest neighbor was $15.1 \mathrm{~m}$. A pair relationship between two of the pikas and a dominance order are discussed. The seasonal progression of the haypiles and the reactions of the pikas to other animals are also noted. 
A BEHAVIORAL STUDY OF A SMALL GROUP OF PIKAS, (OCHOTONA PRINCERS) ON MT. HOOB, OREGON

\title{
by
}

NANCY A. EWEN FRAZIER

\begin{abstract}
A thesis submitted in partial fulfillment of the requirements for the degree of
\end{abstract}

\author{
MASTER OF SCIENCE \\ in \\ BIOLOGY
}

Portland State University 1977 
TO THE OFFICE OF GRADUATE STUDIES AND RESEARCH:

The members of the Committee approve the thesis of

Nancy A. Ewen Frazier presented May 20, 1977.

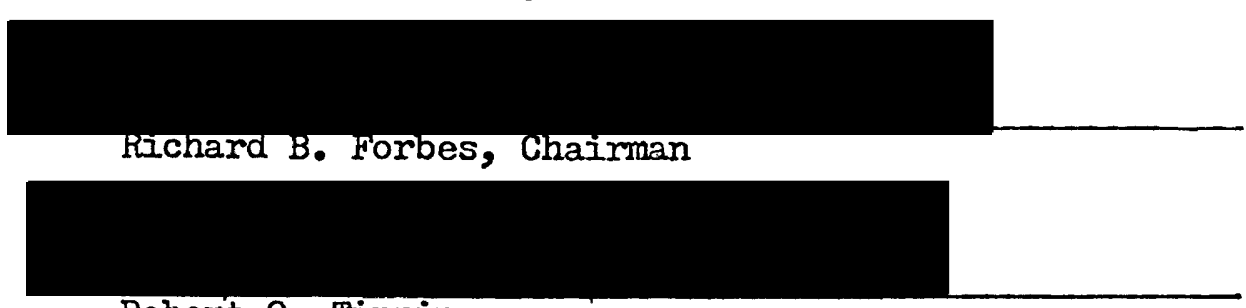

Robert 0. Tinnin

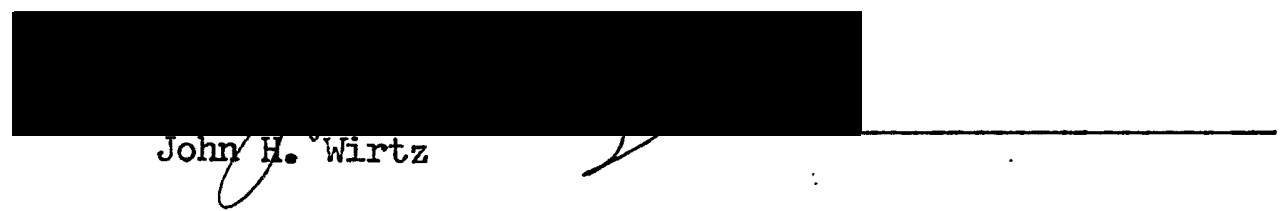

APPROVED:

Herman w. I'aylor, Head, Departmeg of Biology

Stanley: E.:Rauch, Dean of Graduate Studies and Research 


\section{ACKNOWLEDGENENTS}

Gratitude is expressed to the Biology Department, Portland State University for the use of the live traps used in this study. I thank my husband, Brent D. Frazier, for his assistance in the collection of data, and Dr. Richard B. Forbes of Portland State University and Dr. Dave W. Osgood of Butler University for their encouragement and suggestions. I also thank Dr. Robert 0. Tinnin, Dr. John H. Wirtz, and Dr. David Cressler for critically reading the thesis. 


\section{TABLE OF CONTENTS}

PAGE

ACKNOWLEDGEMENTS

iii

IIST OF TABLES

IIST OF FIGURES

vi

INTRODUCTION

DESGRIPTION OF STUDY AREA AND METHODS

Description of Study. Area

Methods

Social Structure and Behavior

Activity Patterns

Haypile Construction.

Interspecific Behavior.

DISCUSSION 


\section{LIST OF TABLES}

TABLE

PAGE

I List of Plants Present at Study Area ................ 9

II Percentages of Total Plant Cover for Each Vertical

Line Transect $\ldots \ldots \ldots \ldots \ldots \ldots \ldots \ldots \ldots \ldots \ldots \ldots \ldots \ldots \ldots \ldots \ldots \ldots \ldots . . \ldots$

III Active Territorial Patterns (after Kawamichi, 1976) ... 13

IV Territorial Size Compared with Other Studies ......... 14

$\nabla$ Changes in Contents of Haypiles; Transcribed from

Field Notes Written on Dates Indicated ............ 22

VI Responses of Pikas to Other Non-predator

Animals $\quad \ldots \ldots \ldots \ldots \ldots \ldots \ldots \ldots \ldots \ldots \ldots \ldots \ldots \ldots \ldots \ldots \ldots \ldots \ldots . \ldots \ldots$ 


\section{LIST OF FIGURES}

FIGURE

PAGE

1 Range of Ochotona princeps in Oregon (Ingles 1965) ..

2: Photo of the Study Area Looking Northwest, 24 January 1977

3 Map Showing the Location of the Study Area

4 Map of the Grid Illustrating the Position of Specific

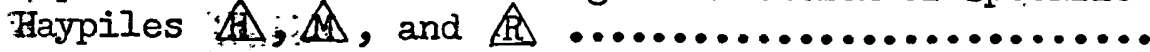

5 Map of the Grid Illustrating the Territories of Pikas $H$ and $M$ Based on Active Territorial Displays

6 Altitudinal Differences in Nearest Neighbor Distances

7 Dominance Hierarchy Suggested from the Observations

8 Percentages of Observed Time Between 0900 - 11:00 Engaged in Given Activities

9 Observed Forage Routes of Pikas 


\section{INTRODUCTION}

The habits of pikas, Ochotona sp. (Lagomorpha: Ochotonidae) have captured the curiosity and interest of biologists for many years as is evident in a review of the literature. Some general aspects of pika natural history have been examined by Severaid (1955), Haga (1960), Krear (1965), and Broajdbooks (1965). Studies have been conducted on the content of their haypiles (Biedleman and Weber 1958, Johnson 1967) and the value of their haypile-building efforts (Johnson and Maxwell 1966, Millar and Zwickel 1972). The gathering of vegetation for haypiles (Kilham 1958, Markham and Wicker 1973, Barash 1973), and the distribution of haypiles (Broadbooks 1965, Smith 1974b, Lutton 1975, Kawamichi 1976), have also been studied in relation to territorial activities. Kawamichi (1969, 1970, 1971a, 1971b, 1976) has studied the social structure and behavior of the Japanese pika (ㅇ. hyperborea yesoensis), two species of Himalayan pikas (‥ macrotis and $\underline{0}$. roylei), and recently a North American species (마 princeps). Daily and seasonal activity patterns were also investigated (Kawamichi 1969, 1971a, Barash 1973, Srath 1974b). Factors influencing pika distribution and dispersal have been examined in recent studies (Bunnell and Johnson 1974, Smith 1974a, $1974 b)$.

Differences in habitat (Bunnell and Johnson 1974) or altitude (Snith 1974b) may alter the activities of pikas: . These differences may be manifested in territorial size (Broadbooks 1965, Barash 1973, Lutton 1975, Kawamichi 1976), perhaps the amount of haypile-building and other 
activity patterns: This study was directed towards observing the daily activities of a group of pikas with respect to the local habitat and noting especially their social behavior.

The pika, Ochotona princeps, occupies talus slopes of boreal montane regions throughout the western half of North America from sea level to alpine meadows. In Oregon (Figure 1), this species is found in the Cascades, and from the Modoc lava beds to Steens Mountain, and in the Blue Mountains (Ingles 1965). Consequently there is much variation in the depth of talus slopes, in the amount of area they cover, in the size of the rocks making up the slope, and in the quantity and quality of the

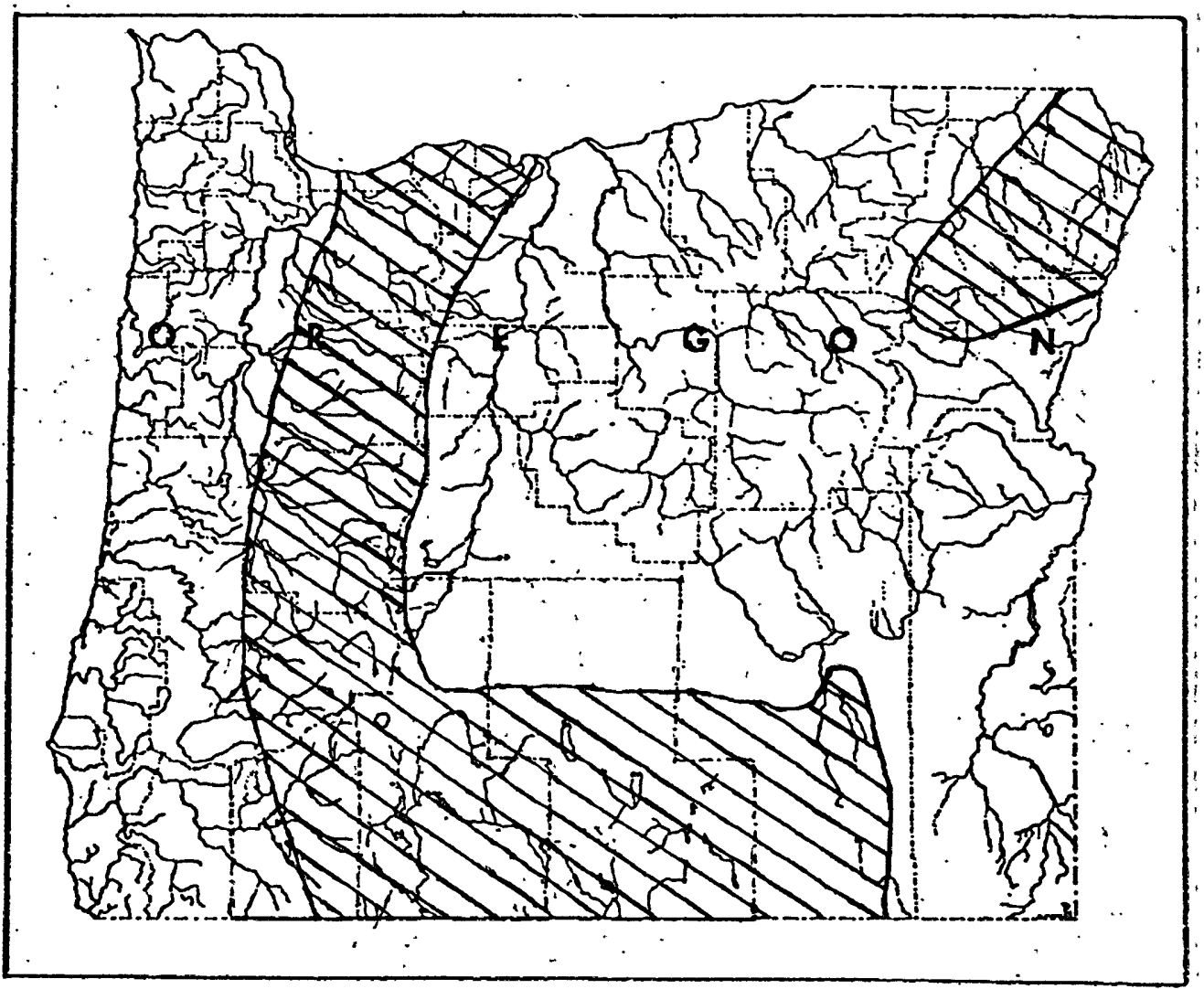

Figure 1. Range of Ochotona princeps in Oregon (Ingles 1965). 
vegetation surrounding them. Suitable pika habitat requires that these areas provide enough vegetation to feed the pikas, and lodging and cover from both predators and weather. Pikas are susceptible to hyperthermia at ambient temperatures greater than $28^{\circ} \mathrm{C}$ (MacArthur and wang 1973); thus the rock slopes or wood piles (Lutton 1975) provide a refuge from both heat and cold. An example of pika habitat in the Cascades is seen in Figure 2.

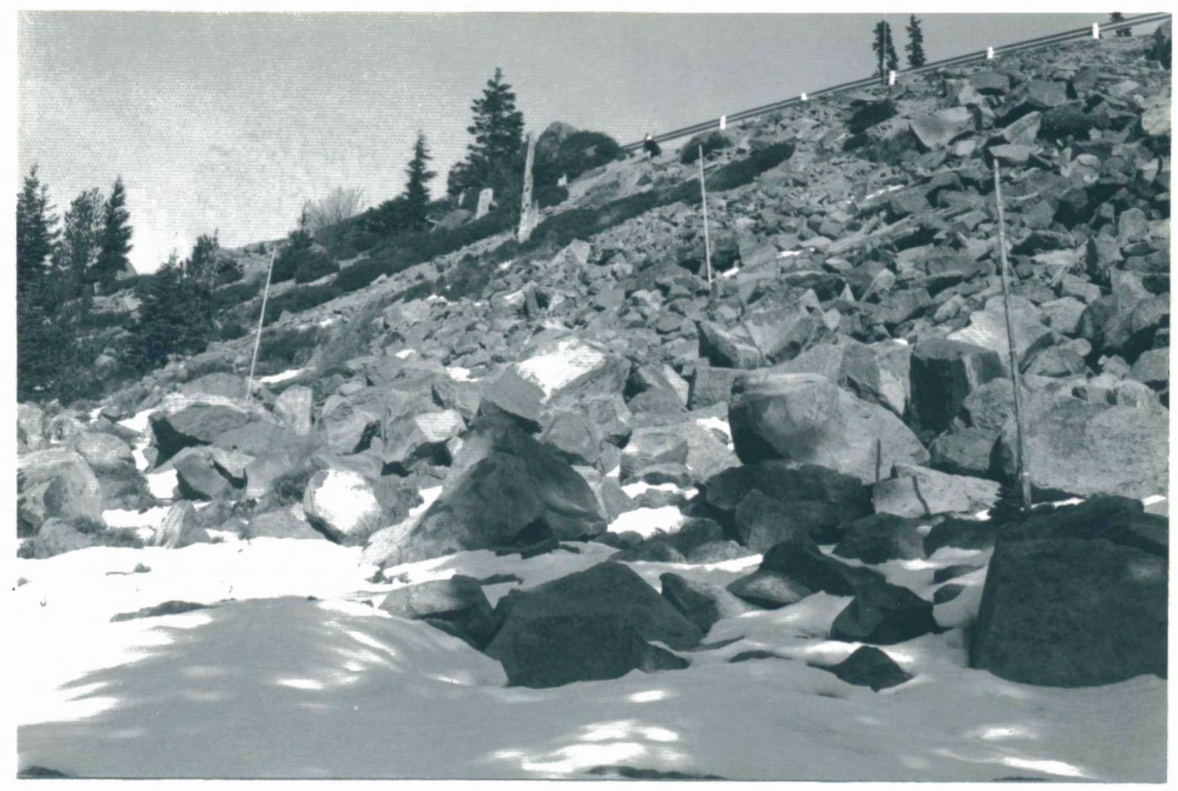

Figure 2. Photo of the study area looking northwest, 24 January 1977: Snowpoles indicate haypiles stored in the rocks. 


\section{DESCRIPTION OF STUDY AREA}

The area used in this study is part of a southwest facing roadfill on Timberline Road, approximately $6.5 \mathrm{~km}$ northeast of Government Camp, Clackamas County, Oregon; SEl/4, NEt/, sec. 18, T3S R9E W. M. (Figure 3). The elevation is $1518 \mathrm{~m}$ at the top of the slope.

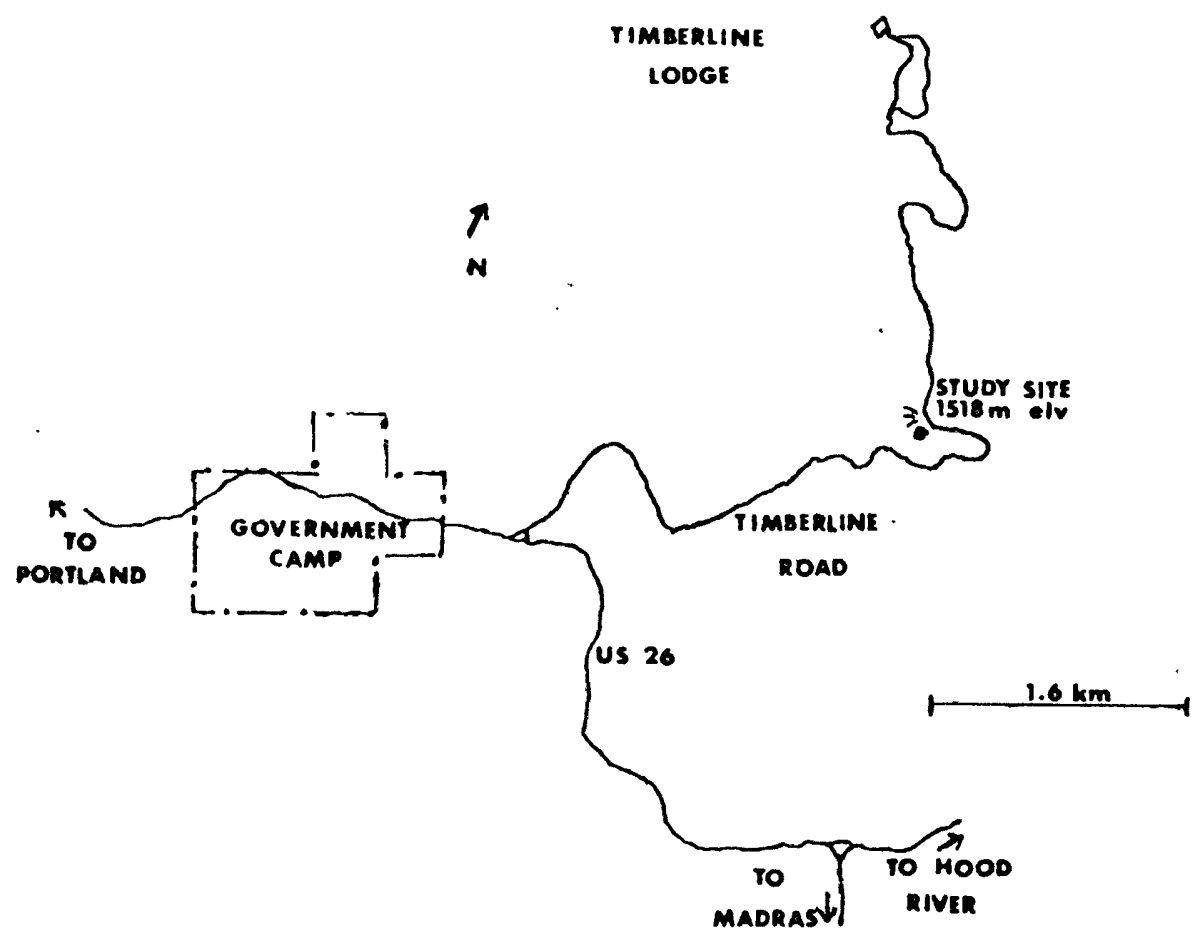

Figure 3. Map showing the location of the study area.

This site was suggested by Keith Turnkill, a U. S. F. S. naturalist at Timberline Lodge. The selection of the site was made on the 
bases of the number of pikas seen or heard while walking across it and by the number and size of the haypiles present. Also the area was readily observable.

\section{METHODS}

Nineteen visits were made to this site between 4 August and 4 November 1976. The first seven of these trips primarily involved exploration, trapping, setting out the grid and vegetation sampling. The remaining trips ( 1 September to 4 November) were spent in observing pikas. The morning hours ( 0800 to $1200 \mathrm{hr}$ ) provided a good time for observation because the activity was most apparent then. An additional trip was made on 24 January 1977. Some observations, made during an earlier (1975-1976) study done with Dr. D. W. Osgood, were also included in this study.

Vegetation was identified by the author using Horn (1972), Randall and Kenniston (1972), and Hitchcock and Cronquist (1973). No specimens were collected. The vegetation within the grid was sampled using the vertical lines of the grid as transects. Plants along the line and within 2-3 cm on either side of it were identified and their cover along the line was measured. From this a percentage of vegetative cover was calculated for each line.

The area was trapped on 18 August 1976. Twelve $5^{\prime \prime}$ X $5^{n}$ X $16^{\prime \prime}$ National live traps with $\frac{3}{4} n \times 1 "$ wire mesh were set close to haypiles, defecation sites, or other places on the slope which had indications of pika activity. The traps, baited with fresh alder leaves and prunes, were set at 1600 PDT and checked at 0700 PDT the next morning. Captured animals were anesthetized with di-ethyl ether and toe-clipped. A clear 
plastic collar was attached about the pika's neck. Colored flagging was attached to the collar for identification purposes. Because of the difficulty involved in sexing pikas in the field, no attempt was made to ascertain the sex of the captured animals, and because of the sensitivity of pikas to trapping and handling, only three were trapped. Had observations indicated a need for further trapping, more attempts would have been made.

A grid was laid out which was $50 \mathrm{~m}$ on one side and tapered from 50 to $30 \mathrm{~m}$ on the other. It was limited by its amount of visually observable area and comprised only a small portion of a roadfill which continued on eastward for about $0.4 \mathrm{~km}$. The base of the grid was bordered by trees and dense underbrush; the top was bordered by loose sand for 10 to $15 \mathrm{~m}$ leading up to the road. The grid was divided into 87 $5 \mathrm{~m} \times 5 \mathrm{~m}$ quadrats; bamboo poles and old highway snowpoles were used to mark the corners. Observation points were located within the grid. Observations were recorded of point locations of the pikas (when possible), the activity in which èch animal wàs engaged, the condition of the pikas, interactions of the pikas with each other and with other animals, the location and movements of other animals, the status and condition of the haypiles and weather conditions.

The locations of haypiles within the grid were mapped and the distances between them were measured. The haypiles were later marked with old highway snowpoles for further winter observations. Locations of defecation stations, cheekrubbing rocks, and forage patterns were also mapped.

The social structure and age structure of the pikas were ascertained from observations. An activity pattern was charted for two pikas as 
part of their total individual active time. Also charted were the reactions of the pikas to other animals and active territorial patterns.

'The percentages of different vocal patterns used in territorial responses by both occupants and invaders were calculated.

Three methods for estimating the size of the territory were employed in this study. The first method was to plot the observed positions of active territorial behavior on graph paper and to count the squares within the points to determine the area covered. The second method, a density probability function (Calhoun and Casby 1958), was used only for comparative purposes. It is more accurately used in the calculation of home range size, and its application here is purely of a speculative nature. The home range was not calculated. A third estimate was determined by calculating the mean distances to the nearest neighbor using the distances between the haypiles to represent the distance between neighbors (Smith 1974b). 


\section{RESULTS}

Based on the vegetation sampled, beargrass (Xerophyllum tenax (Pursh) Matt.) appeared to predominate in terms of vegetative cover. ' In all but two transects the percentage of total vegetative cover was greater for it than any other plant (Table II). A list of the plants observed in the area is given in Table $I$. No boxwood (Pachistima myrsinites (Pursh) Raf.) was found below the edge of the rock slope east of vertical Iine 35. The boxwood in line one was. Iocated at the top: of the slope. As this was primarily a behavioral study no further analysis of the vegetation was attenpted.

Three pikas were trapped on 18 August 1976. Two of these ( $H$ and R) were trapped within ten meters of each other (Figure 4). A third pika (M) was caught at the base of the slope. All the animals were in good condition. A small unmarked immature pika was seen on the western edge of the grid ( 30 vertical, +30 horizontal). One pika was seen in the eastern end of the grid at the base of the slope. However most of the the activity within the grid involved the three pikas which were trapped and centered around their haypiles.

\section{SOCIAL STRUCTURE AND BEHAVIOR}

Pika $R$ was assumed to be a female, and pikas $H, M$, and $C$ males, based on the fact that female pikas apparently do not utter long calls (Severaid 1955, Krear 1965, Kawamichi 1976). Pikas R and H were considered to be adults and pika $M$ a jurvenile. Pika $M$ was grayer and smaller 
TABLE I

IIST OF PLANTS PRESENT AT STUDY AREA

Beargrass (Xerophyllum tenax (Pursh) Nutt.)

Bleeding iheart (Dicentra uniflora Kell.)

Dwarf bramble (Rubus Iasiococcus Gray)

Rock-brake (Cryptogramma crispa (I.) R. Br.)

Swordferm (Polystichwn sp. Roth)

Oregon boxwood (Pachistima myrsinites (Pursh) Raf.)

Huckleberry (Vaccinium scoparium Leiburg)

Huckleberry (Vaccinium membranaceum Dougl•)

Mountain hemlock (Tsuga mertensiana (Bong.) Carr.)

Lodgepole pine (Pinus contorta Dougl.)

Whitebark pine (Pinus albicaulis Engelm.)

Subalpine fir (Abies lasiocarpa (Hook.) Nutt.)

Fir (Abies sp. Mill)

Grass (not identified)

Moss (not identified) 


\section{TABLE II}

PERCENTAGES OF TOTAL PLANT COVER FOR

EACH VERTICAL IINE TRANSECT

\section{Plant \\ Percentages / line}

$\begin{array}{lllllllllll}1 & 2 & 3 & 4 & 5 & 6 & 7 & 8 & 9 & 10 & 11 .\end{array}$

Xerophyllum tenax $>5 \mathrm{~cm}$

$\begin{array}{lllllllllll}25 & 67 & 59 & 36 & 47 & 55 & 41 & 29 & 52 & 56 & 50\end{array}$

Xerophyllum tenax $<5 \mathrm{~cm}$

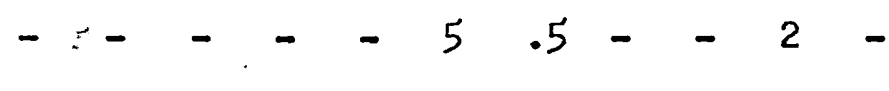

Dicentra uniflora

- - - - 21038 - 1

Rubus lasiococcus

$-\quad-121.454433$

Cryptogramma crispa

Polystichum sp.

Pachistima myrsinites

75276 - - - 671226

Vaccinium scoparium

$\begin{array}{lllllllll}- & 6 & 6 & 31 & 17 & 13 & 14 & 1 & 21\end{array}$

Vaccinium membranaceum

- $\quad 326141917421549$

Tsuga mertensiana

$-\quad 14-2-7.6-1.2-$ -

Pinus contorta

$-\quad-\quad-\quad 5-11-\therefore$

Pinus albicaulis

- $-\quad$ 84.- - -

Abies sp,

Grass

Moss

$-\quad 954----.6-$ 


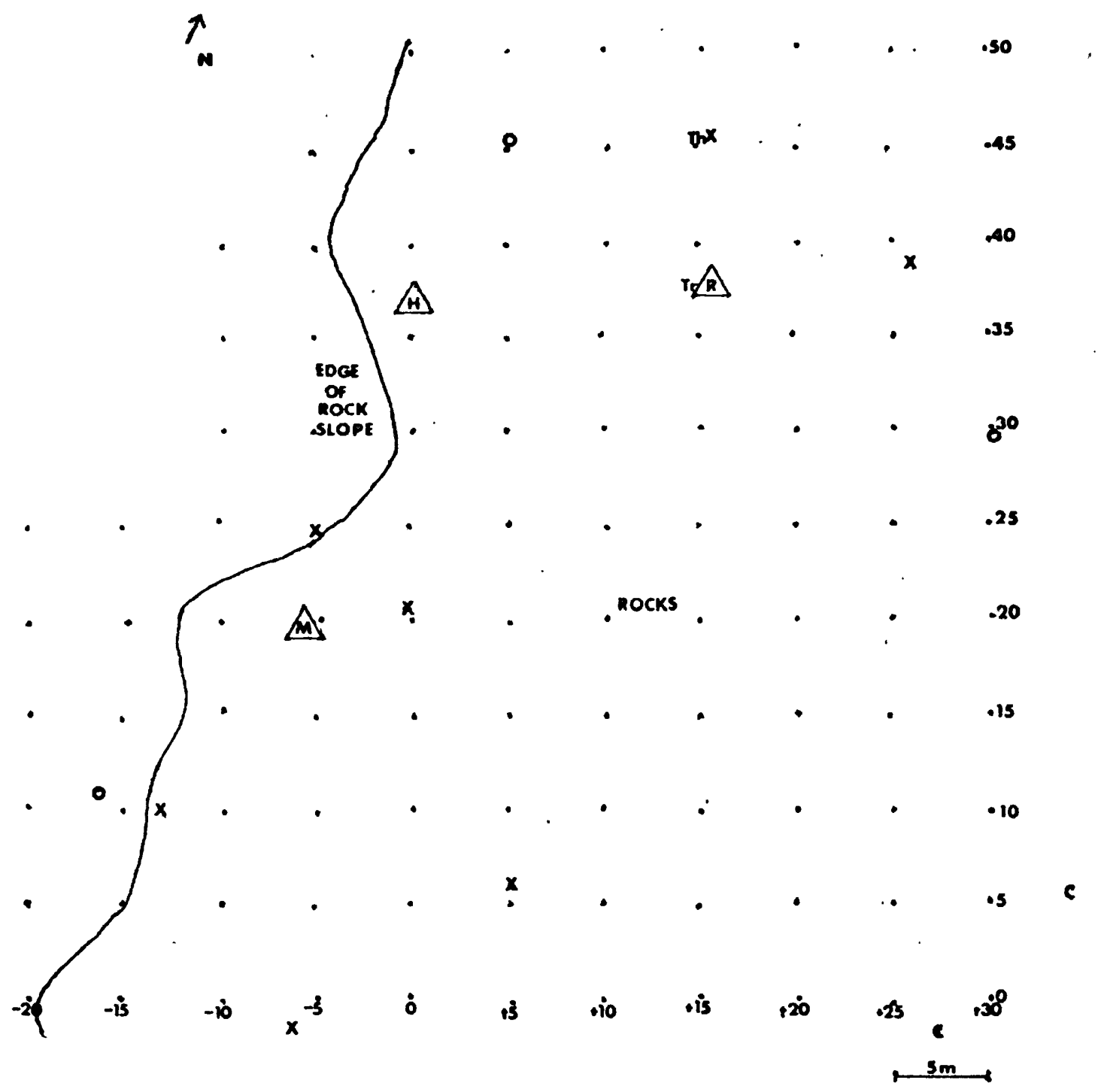

Figure 4. Map of the grid illustrating the position of specific haypiles $A, A$, and $A$. Also represented are the capture sites, Th and $T r$, other pikas, 0 , defecation stations, $X$, and scattered clippings of vegetation found under the rocks, $C$. 
than either of the other two. He also wandered about the lower part of the slope. Two weeks after capture he appeared to be larger and his pelage was a buffy brown like pikas $H$ and $R$ (this was different from the molt which 211 three pikas underwent at the end of September). He also showed signs of territorial behavior, uttering long calls and using the area around an. old haypile for his own through hoarding of vegetation and for other activities.

The territorial behavior of pikas can be divided into two forms, active and passive. Passive territorial behavior includes such things as cheek-rubbing (the marking of rocks with secretions from the apocrine gland of the cheek), and the deposition of urine and feces at certain locations. The latter two. were found to be of territorial significance in Oryctolagus (Mykytowycz 1968) and have been suggested to be so for pikas as well (Kilham 1958). However no clear distinction of territorial boundaries was apparent from defecation and urine stations (Figure 4). Active behavior included retreat from, approach or chasing of another pika, a vocal exchange, or simply watching. The observed patterns are in agreement with those noted by Kawamichi (1976), and they ar are presented in Table III, taken from his paper. In the present study, long calls consisted of a "chattering" vocalization lasting for a period of about 20 seconds; short calls lasted 0.25 seconds (Barash 1973). The observed behavior frequently involved more than one of these patterns and sometimes occurred in a sequence.

The importance of calling in defining territorial boundaries was noted by Broadbooks (1965). In the present study, the Iong call was given more in defense responses (42\%) than in invasion (17\%). Invaders 
TABLE III

ACTIVE TERRITORIAL BEHAVIOR PATTERNS

(AFTER KAWAMICHI, 1976)

Behavior of occupant

Behavior of invader

Indifference to an invader

Long vocal response*

Iong vocal response with a return to the haypile*

Quick approach to an invader

Slow approach to an invader

Watching

Short rocal responsex

Retreat from the invader (hiding) Chasing the occupant
Indifference to an occupant

Short vocal response*

Iong vocal response followed by an advancex

Quick retreat from an occupant

Slow retreat from an occupant

Watching

Long vocal response*

* Patterns which were observed in the present study but were not used by Kawamichi (1976).

frequently gave short calls (53\%). These often preceded a long call from the occupant and then followed either an exchange of short calls or an advance and retreat situation.

Classically, "territory" is applied to any area wich is defended (Noble 1939). Thus, only those pikas which exhibited an exchange of long calls or physically defended their territory by making advances on another pika were considered for territorial size estimaties:. This meant that territories could be calculated for pikas $H$ and $M$ only. Pika $R$ did not defend her haypile and did not utter a long call. Pika $C$ 
exhibited some territorial behavior but it was not used due to the lack of observations of this pika.

Figure 5 shows that the onserved territories of pikas $H$ and $M$ were $305.5 \mathrm{~m}^{2}$ and $121 \mathrm{~m}^{2}$ respectively. These are lower than other studies have indicated (Table IV). In applying the density probability function techniques (Calhoun and Casby 1958). used in calculating circular home ranges, pika $H$ would have a sigma value of $6.7 \mathrm{~m}$ from observed. territorial responses. This would yield an area of $140.95 \mathrm{~m}^{2}$. The actual observed territory was approximately 1.5 sigma. If the territory observed is assumed to be only a part of the total territory (similar to Calhoun and Casby's assurmptions on home range), then by using three sigma a territion of $1268.6 \mathrm{~m}^{2}$ is calculated for H. A mean for both pikas is calculated to be $1107.0 \mathrm{~m}^{2}$. Both of these estimates are within the limits of the other studies.

\section{TABLE IV}

TERRITORIAL SIZE COMPARED WITH OTHER STUDIES

Study

Broadbooks (1965)

Barash (1973)

Iutton (1975)

Kawamichi (1976)

Mt.ifHood (1976)
Territory $\left(m^{2}\right)$

$$
\begin{aligned}
& 3457.2 \text { (max.) } \\
& 3000-4000 \\
& 400 \\
& 708.55 \text { (range } 319-1365 \text { ) } \\
& 215.75 \text { (mean) }
\end{aligned}
$$




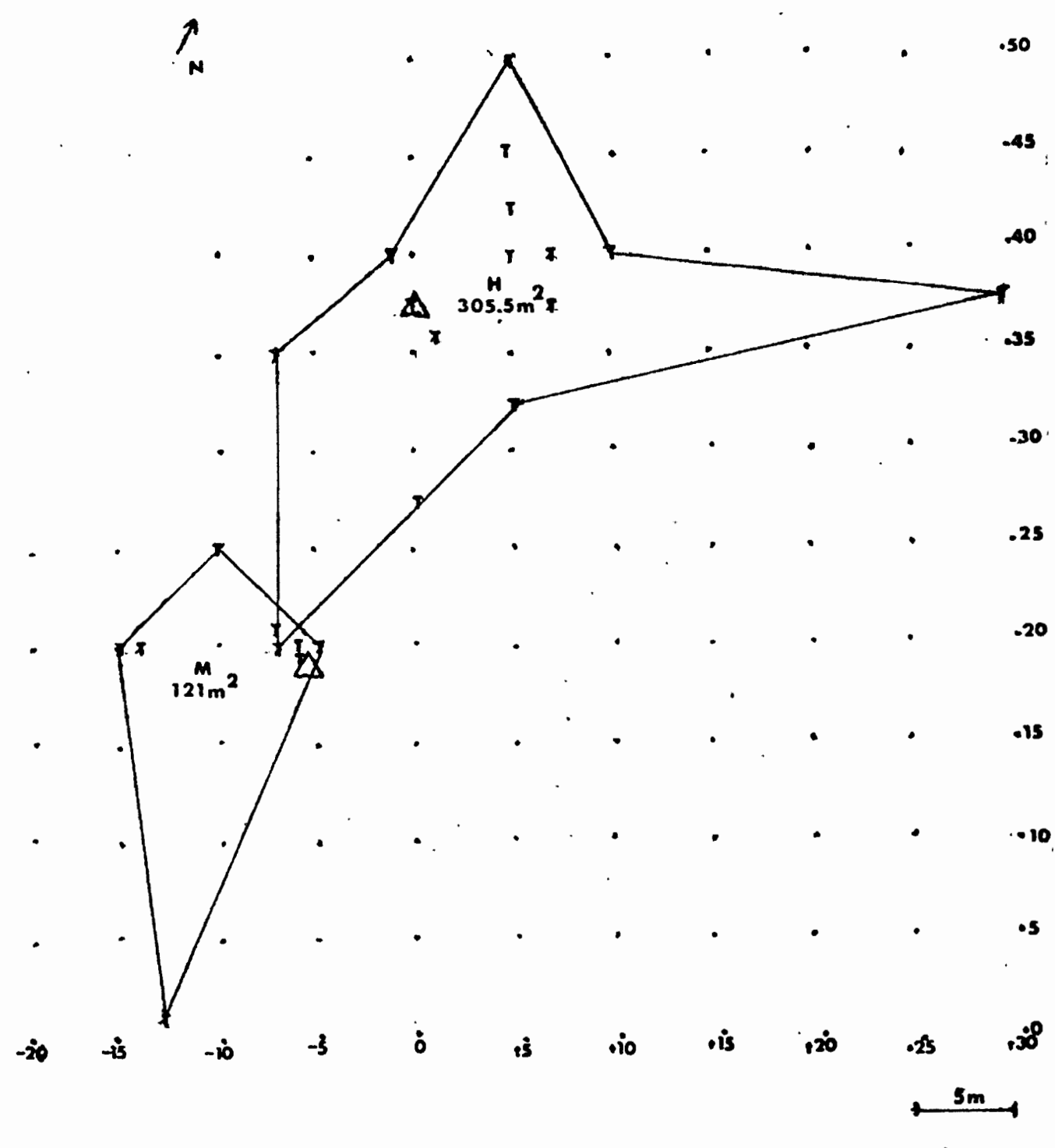

Figure 5. Map of the grid illustrating the territories of pikas I and $M$ based on active territorial displays. T indicates the point at which the display was observed. $\Delta$ indicates a haypile. 
Smith (1974b) has suggested that nearest neighbor distances at high altitudes are greater than those at low altitudes, due to a decreased mobility of the pikas at low altitudes as the result of greater heat stress. In graphing the distance between haypiles from this study with those given in his study, there does appear to be a positive relationship between territorial spacing and altitude (Figure 6). In Broadbooks (1965)"stridy, the rise of the line is steeper, but the same relationship exists.

Territorial interactions suggested that $H$ was dominant over the other pikas in the grid. During their first encounter ( 31 August) $M$ was close to H's haypile, before M showed signs of possessing a territory. H chased M $10-15 \mathrm{~m}$ away from the haypile. This was repeated three times within one hour. Ten days after this ( 9 September), Mras using an old haypile which was $16.4 \mathrm{~m}$ from $\mathrm{H}^{\prime} \mathrm{s}$. Once during this day $\mathrm{H}$ and $\mathrm{M}$ were close to one another in the forage area below the grid. There was a vocal exchange between the two and both returned to their haypiles. H then went to $M$ 's haypile and chased $M$ away. M responded by calling softly from beneath the rocks and circling the haypile at a distance of $5 \mathrm{~m}$. H finally returned to his haypile. On 23 September $\mathrm{H}$ was in the forage area below the grid again and $M$ was close to his own haypile. M uttered a long call while looking toward $H$ in the forage area. M made a slow adrance in that direction. Four minutes later, $H$ had returned to his haypile area and did not make any advances towards M's area. In a similar manner, H chased $C$ about the top of the grid, 25 - $30 \mathrm{~m}$ from H's haypile. $C$ uttered a long call once when Hi was in his area but was nerer observed to chase $H$. On three occasions $R$ was seen entering H's 
Distance in

(in) to nearest neighbor

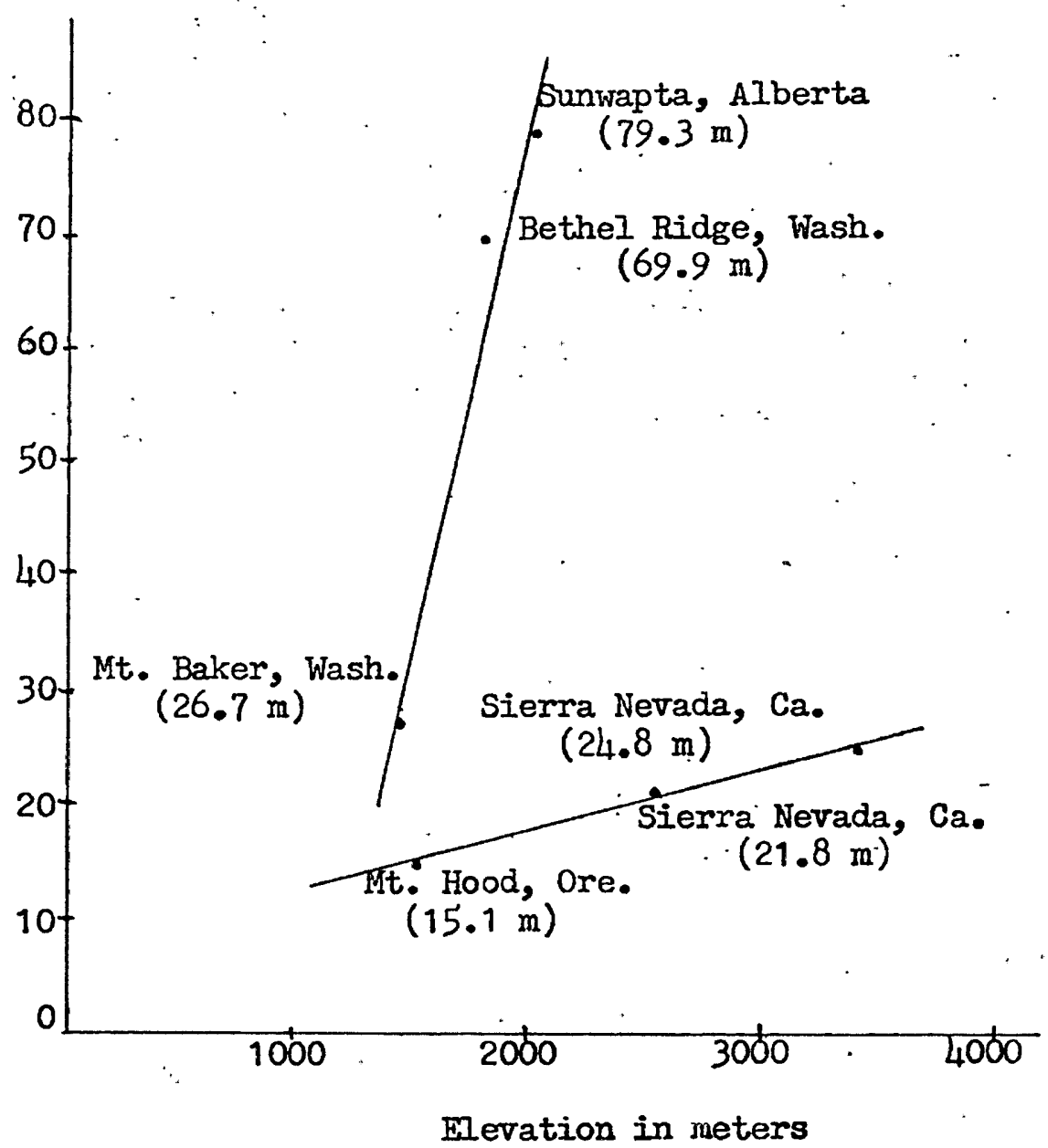

Figure 6. Altitudinal differences in nearest neighbor distances. Data for other than the present study are from Broadbooks (1965) and Smith (1974b). 
territory, and each time brought a verbal rebuke from $H$ and a return to the respective haypiles. $R^{\prime}$ 's haypile was located $14.4 \mathrm{~m}$ from H's. R would often give a short call from her haypile which would be answered by a long call from $\mathrm{H}$ and a return to his haypile if he was away from it. $R$ responded to this by disappearing under the rocks at her haypile and on one occasion left the haypile area. These observations are consistent with a dominance hierarchy scheme as shown in Figure 7.

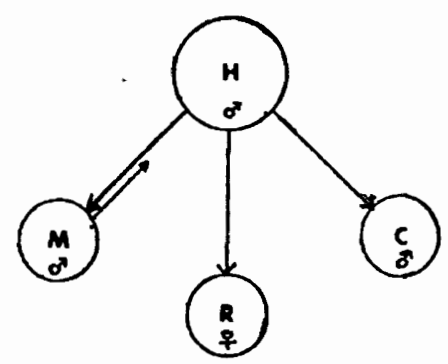

Figure 7. Dominance hierarchy suggested from the observations.

Pikas $R$ and $H$ also appeared to be a pair. This assumption is based on $R^{\prime} S$ tolerance of $H$ at or close to her haypile. Five times he was seen at her haypile or close to it, while she was also present. On one of these occasions $H$ entered the haypile, she watched him and then followed him. At other times they watched each other from short distances ( $5 \mathrm{~m}$ or less). As already noted, $\mathrm{H}$ responded to short calls from $R$ by uttering a long call and returning or staying close to the haypile. Frequently they would chatter back and forth between the haypiles until $\mathrm{R}$ usually disappeared. $\mathrm{H}$ tolerated $\mathrm{R}$ moving through his territory enroute to forage. He also responded to long calls given by male pikas which were close to R's area. On 30 September, $R$ gave a short call from 
at about $8 \mathrm{~m}$ away from her haypile. H answered with a long call from within - 5 -m of his haypile; another long call was given by pika $c$ at the top of the grid ( 30 vertical, +32 horizontal). Within two minutes $H$ was at the top of the grid where $C$ had been and $R$ was at her haypile. This happened one other time. From this evidence it appeared that $H$ was possibly $R^{\prime} s$ "protector". To test this I walked in front of $R^{\prime} s$ haypile when $I$ knew that both $R$ and $H$ were at home. " $R$ gave a short alarmed call from within the rocks. H came out from his haypile calling and started up the slope towards R's haypile but stopped as soon as he saw me and continued to call.

\section{ACTIVITY PATTERNS}

A comparison of the activities of $H$ and $R$ during the hours of 0900 - 11.00 for six separate days in September and October also emphasizes the difference in time spent engaged in territorial activities (Figure 8). The territorial activity of $R$ mainly involved making short calls or times when she was invading H's territory (separate from being enroute to the forage area), or cheek-rubbing. The amount of time engaged in foraging or feeding is about the-same for each. They both maintained active haypiles so this would be expected. Often times the pika would perch on a rock and remain there watching for as much as 40 minutes. During this time they would often groom themselves or practice autocoprophagy, but usually they would sit motionless. This form of behavior has been referred to as "musing". (Kawamichi 1969, 1971a). All of:. the pikas observed did this.

The pikas were especially active in foraging and feeding during 


\begin{tabular}{|c|c|c|c|c|}
\hline & $\begin{array}{l}\text { TERR } \\
30\end{array}$ & $\begin{array}{c}\text { FOR/FEED } \\
-21 .\end{array}$ & $\begin{array}{c}\text { MUS ING. } \\
\text { ab }\end{array}$ & ORH \\
\hline $\begin{array}{l}\mathbf{1} \\
4\end{array}$ & $\begin{array}{c}\text { FOR/FEED } \\
24\end{array}$ & & & \begin{tabular}{l|l}
5 & ond \\
$\frac{3}{3}$ & 5
\end{tabular} \\
\hline
\end{tabular}

Figure 8. Percentages of observed time between 0900-1100 engaged in given activities. T, Terr = territorial, For $/$ Feed $=$ foraging and feeding, Oth = motion from one place to another and miscellaneous, $C=$ calling (other than territorial).

the morning hours. The number of times they were observed partaking in this activity was five times greater in the morning than in the afternoon. Pikas, like most other lagomorphs, are autocoprophagous; much of their feeding time in the morning was spent in this practice, usually on a rock near their haypiles. Foraging activity involved the collection of vegetation for the haypile and for consurmption. Each animal had definite areas in which it foraged and definite routes for getting there and back (Figure 9).

\section{HAYPILE CONSTRUCTION}

Haypiles are probable indicators of the forage area of a pika. The haypiles observed in this study contained mostly the vegetation which was available in the immediate area of the haypile. Only one main haypile was located for each of the three pikas and only that part of the haypile which was outwardly visible was examined. A description of each haypile is given in Table $\nabla$. The, haypile east of the grid was located at the base of the rock pile and was within $2 \mathrm{~m}$ of the forage area This area was cioser to the trees which probably accounts for 


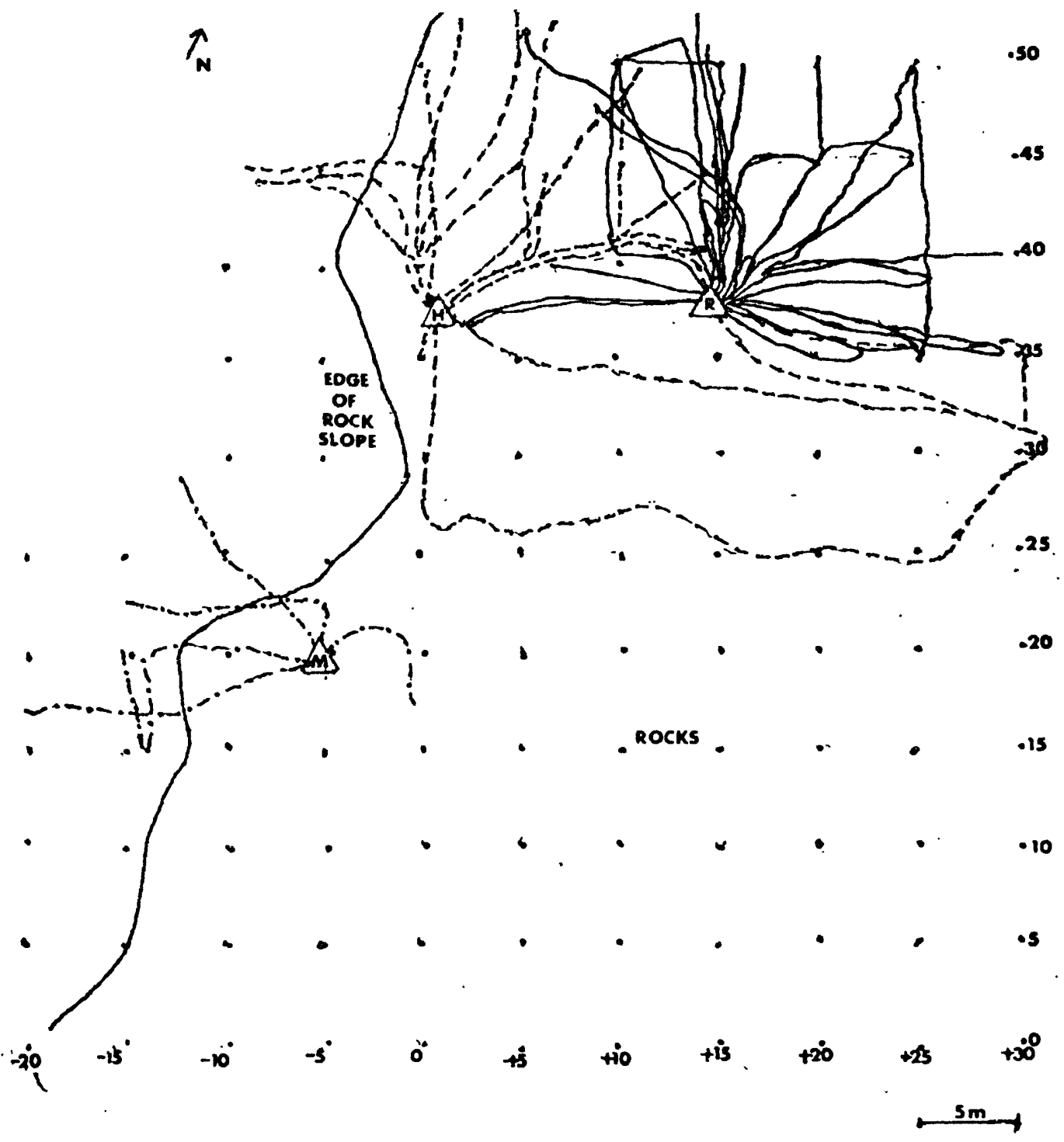

Figure 9. Observed forage routes of pikas $H, M$, and $R_{\text {. }}$ H's routes are marked with a dashed line, M's routes are marked with dot-dash-dot, and $R$ 's routes are marked with a solid line. $A, A$, and indicate the respective haypizes. 
TABLE V

CHANGES IN CONTENTS OF HAYPILES; TRANSCRIBED FROM

FIELD NOTES WRITTEN ON DATES INDICATED

\begin{abstract}
August 4 . No large haypiles; scattered clippings.
August 18-19 Two fresh haypiles containing fresh black huckleberry, red huckleberry, bleeding heart, and a small amount of beargrass were located.
\end{abstract}

September 9 Old haypile located at 20v, $-6 \mathrm{~h}$ and adopted by M.

September 16 . M's haypile small compared to the other two; contained black huckleberry, red huckleberry, and some boxwood.

R's haypile contained boxwood, a small amount of beargrass clippings, and bleeding heart blossoms and leaves:

H'S haypile contained beargrass and black huckleberry but was mostly made up of bleeding heart leaves. The beargrass was fresh growth:

October 6 Rock-brake fern and beargrass were new additions to M's haypile.

October 13 .. M!s haypile was: scateered in crevices under a large rock. It contained rock-brake fern, huckleberry- bleeding heart, beargrass, and: small amounts: of conifer. There appeared to be an auxilliary runway on the down, slope side of this rock which contained old clippings and scats. The rock-brake fern was clipped off at $20 \mathrm{v}, 0$ and there was a large pile of scats found here also.

$R^{\prime} s$ haypile was contained in a series of caverns and was also located under a large rock. The materials in it were boxwood, bleeding heart, some huckleberry, and some beargrass. There was a large pile of scats $7.5 \mathrm{~cm}$ deep cov-: ering the bottom of the entrance.

H's haypile was also located under a large rock. The haypile contained huckleberry, bleeding heart, boxwood, and beargrass in varying proportions, but the beargrass was predominant: (H was seen several times arranging the vegetation in his haypile).

A haypile was located $25-30 \mathrm{~m}$ east of the grid under a large rock:- Haying materials consisted of large amounts of twigs, layered with huckleberry, and hemlock twigs. Marmot scats and pika:scats and urine: stains were found. 
the large number of twigs found in it. A seasonal progression of haypile contents was also noted. When checked in January, $R^{\prime} s$ haypile contained recent boxwood clippings and H's haypile was almost reduced to bare twigs on the sides which had contained the boxwood and huckleberry. The beargrass around the haypile had been freshly clipped; that in the haypile was dried. M's haypile was partially covered by snow; no evidence of use was seen. The large haypile located east of the grid contained a few fresh clippings of boxwood but was otherwise reduced to bare twigs.

\section{INTERSPECIFIC BEHAVIOR}

Other non-predator animals which utilized the rock slope were golden-mantled squirrels (Spermophilus lateralis), Townsend's chipmunks (Eutamias townsendii), pine squirrels (Tamiasciurus douglasii), and yellow-bellied marmots (Marmota flaviventris). Dark-eyed juncos (Junco hyemalis), Stellar's jays (Cyanocitta stelleri), Clark's nutcrackers (Nucifraga columbiana), and common flickers (Colaptes auratus), were also occasional visitors. The reaction of the pikas to these animals varied but most often there was no reaction at all (Table VI). The chipmunks and ground squirrels were observed to run through $H^{\prime} s$ and $M^{2} s$ haypiles, but this brought no reaction unless the pikas were directly confronted when they were close to the haypile. Then they responded rocally and either advanced or retreated. Calling was the second most observed response. On one occasion $M$ responded to a marmot that had entered its territory by calling softly and remaining under the rocks. Pikas $H$ and $R$ were perched on rocks near their haypiles at this time and remained 
there watching. As the marmot entered H's territory, $\mathrm{H}$ began calling. The marmot moved up line 35 vertical towards another marmot which originally had been $2 \mathrm{~m}$ above pika $R$. $R$ had disappeared beneath the rocks and the marmots did also. The only. other times $M$ had given such a reaction were when $H$ entered his territory or when a long-tailed weasel (Mustela frenata) was in the grid.

\section{TABLE VI}

RESPONSES OF PIKAS TO OTHER NON-PREDATOR ANTMALS

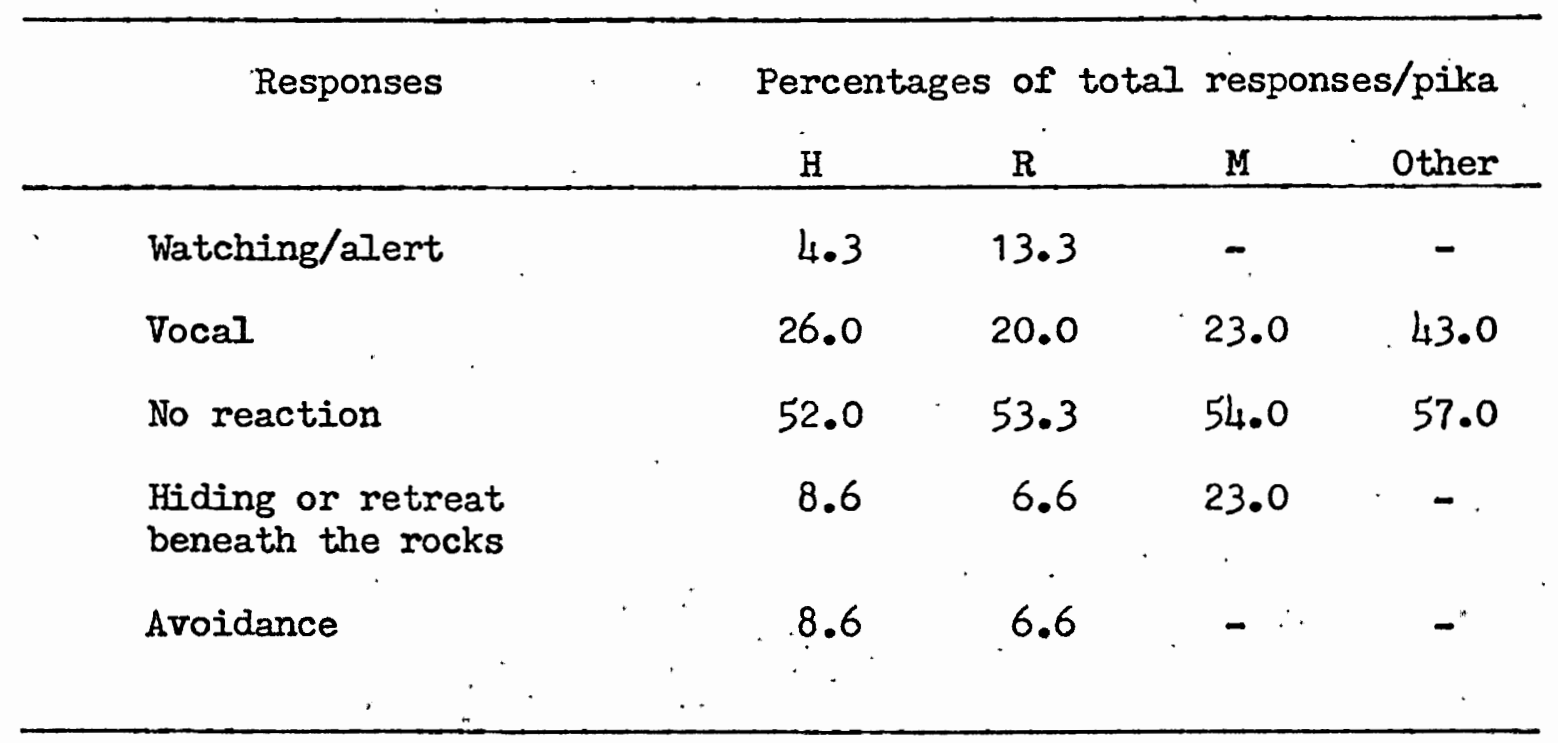

The predators seen were a long-tailed weasel (Mustela frenata), a red-tailed hawk (Buteo jamaicensis), à golden eagle (Aquila chrysaetos), and ravens (Corvus corax). When the larger birds flew over the grid: none of the marked pikas were visible, so it is not possible to say what the pikas reactions to these predators would have been. However, an unidentified pika did call when the eagle flew over the grid. $R$ responded by calling when a raven flew over and all three pikas $H, M$, and $R$ remained wary and watching. The weasel was observed entering the rocks 
from the trees below the grid. He moved through the rocks and entered M's haypile. $M$ was also in this area and could be heard giving muffled calls from beneath the rocks. The weasel then moved up line 20 vertical to +15 horizontal and eastward out of the grid. It was half an hour until $M$ was seen again. This vocal response to a weasel in the rock slope is in contrast to earlier reports by Broadbooks (1965) and Lutton (1975). 


\section{DISCUSSION}

There are several problems involved in determining the activity patterms of pikas. The primary problem is one of visibility. Judgments must be made when the animal is aboveground and clearly visible, which gives only a partial picture of the total pattern. Telemetry equipment similar to that which was used in the study done with Dr. Osgood would be helpful in solving this problem. Another problem is the influence of variables such as the presence of predators, the presence of the investigator, or changes in weather. "It is difficult to determine what. effect these have on the actions of the pikas. Again telemetry equipment could be useful:

0. princeps has been observed to be territorial during the haying season but not during the breeding season (Barash 1973, and Iutton 1975). Based on the territorial displays given by female pikas during the late summer and early autumn months, it has been inferred that no paired relationships exist in 0 . princeps beyond the early summer mating season (Barash 1973, and Lutton 1975). Kawamichi (1976) observed some pairing in 0. princeps in the fall, but noted that it was less defined for this species than for the Asian species 0 . hyperborea yesoensis. He attributed the difference to a greater territoriality in 0 . princeps. in relation to their haypiles. The observations made in this study also support the existance of a paired relationship. However, each pika maintained its individual haypile. The, lack of territorial defense by $R$ is an unusual occurrence. In the previous territorial studies (Barash 1973, Lutton 
1975, and Kawamichi 1976), aggressive behavior by both sexes was observed. But in considering H's possible role as "protector," and the suggested wider spacing between the territories of females (Kawamichi 1976), R would not need to defend her territory.... The subject of pair bonds should be pursued in future studies.

Kawamichi (1976) noted that adult $\underline{0}$. princeps were dominant over the juveniles, and the males were dominant over the females of the same age group. This order of rank was observed in part in the present study; the dominance of pika $H$ over pikas $R$ and $M$ was clearly demonstrated, but no interaction was observed between $R, M$, and $C$.

As mentioned earlier, differences in habitat or altitude may af: fect the pikas. "Bunnell and Johnson (1974) used regression analysis to compare pika habitats of similar character and determine which physical factors influenced the pika population:- In many cases; though, - it is: similarities which are sought from widely varying study areas. Differences in these areas (available forage, size:and strueture of the area) are probably reflected in the activity patterns and the spacing of the pika population, and are partly responsible for the differing estimates of territorial size. The estimates of territorial size obtained in this study are low, but perhaps they are appropriate for the conditions of the study area. 


\section{SUMMARY}

A paired relationship existed between two pikas during the fall haying season. Dominance of one male pika over a female and two other males was observed. Territories for the dominant male and one of the other males of $305.5 \mathrm{~m}^{2}$ and $121 \mathrm{~m}^{2}$ respectively, were determined from territorial displays. A mean distance to nearest neighbor value of $15.1 \mathrm{~m}$ was determined using the distances between haypiles to represent the distance between neighbors. 


\section{REFERENCES CITED}

Barash, D. P. 1973. Territorial and foraging behavior of pika (Ochotona princeps) in Montana. Am. Mid. Nat. 89: 202-207.

Beidleman, R. G. and W. A...Weber.. 1958. Analysis of a pika hay pile. J. Manm: 39: 599-600.

Broadbooks, H. E. 1965. Ecology and distribution of the pikas of Washington and Alaska. Am. Mid. Nat. 73: 299-335.

Bunnell, S. D. and D. R. Johnson. 1974. Physical factors affecting pika density and dispersal. J. Marm. 55: 866-869.

Calhoun, J. B. and J. U. Casby. 1958. Calculation of home range and density of small mammals. Publ. Health Monog. No. 55. 24 p.

Haga, R.- 1960. Observations of the ecology of the Japanese pika. J. Marm. 41: 200-212.

Hitchcock, C. I. and A. Cronquist:. 1973. Flora of the Pacific Northwest. Univ of Washington Press, Seattle. 730 p.

Horn, E. I. 1972. Wildflowers 1. Touchstone Press, Bearerton, Oregon. $160 \mathrm{p}$.

Ingles, L. G. 1965. Marmals of the Pacific states. Stanford Univ. Press, Stanford. $506 \mathrm{p}$.

Johnson, D. R. and M. H. Maxwell. 1966. Energy dynamics of Colorado pikas. Ecology 47: 1059-1061.

Johnson, D. R. 1967. Diet and reproduction of Colorado pikas. J. Mamm. 48: $311-315$.

Kawamichi, T. 1969. Behaviour and daily activities of the Japanese pika Ochotona hyperborea yesoensis. Jour. Fac. Sci. Hokkaido Unit." Ser. VI, Z001. 17: 127-151.

- 1970. Social pattern of the Japanese pika, Ochotona hyperborea yesoensis, preliminary report. Jour. Fac. Sci. Hokkaido Univ. Ser. VI, Zool. . 17: 462-473.

- 1971a. Daily activities and social pattern of two Himalayan pikas, Ochotona macrotis and 0 . roylei, observed at ít. Everest. Jour. Fac. ScI. Hokkaido Univ- Ser. VI, Zool. 17: 587-609. 
- 1971b. Annual cycle of behaviour and social pattern of the Japanese pika, Ochotona hyperborea yesoensis. Jour. Fac. Scid

Hokkaido Univ. Ser. VI, Zool. 18: 173-185.

- 1976. Hay territory and dominance rank of pikas (Ochatona princeps). J. Marm. 57: 133-148.

: Kilham, L. 1958. Territorial behavior in pikas. J. Marm. 39: 307.

Krear, H. R. 1965. An ecological and ethological study of the pika (Ochotona princeps saxatilis Bangs) in the Front Range of Colorado. PhD thesis Univ. of Colorado, Boulder. $329 \mathrm{p}$.

Lutton, L. M. 1975. Notes on territorial behavior and response to predators of the pika, Ochotona princeps. J. Marm. 56: 231-234.

MacArthur, R. A. and L. Wang. 1974. Behavioral thermoregulation in the pika Ochotona princeps: a field study using radiotelemetry. Can. J. Z001. 52: 353-358.

Markham, 0. D. and F. W. Whicker. 1973. Notes on the behavior of the : pika (Ochotona princeps) in captivity. Am. Mid. Nat. 89: 192-199.

Millar, J. S. and F. C. Zwickel. 1972. Characteristics and ecological significance of hay piles of pikas. Marmalia 36: 657-667.

Mykytowycz, R. 1968. Territorial marking by rabbits. Sci. Am. 218: $116-126$.

Noble, G. K. 1939. The role of dominance in the life of birds. Auk 56: $263-273$.

Randall, W. R. and R. F. Keniston. 1971. Manual of Oregon trees and shrubs. OSU Book Stores Inc., Corvaliis.

Smith, A. T. 1974a. The distribution and dispersal of pikas: Con-y sequences of insular population structures. Ecology 55: 11121119.

- 1974b. The distribution and dispersal of pikas: influences of behavior and climate. Ecology 55: 1368-1376.

Severaid, J. H. 1955. The natural history of the pika (Marmalian gemus Ochotona). PhD Thesis, U. of Calif., Berkeley. $820 \mathrm{p}$. 